\title{
What can we learn about wellbeing in school?
}

\author{
Anne Kathryn Soutter \\ PhD student \\ School of Educational Studies and Human Development \\ University of Canterbury \\ New Zealand
}

\begin{abstract}
In recent years, the term wellbeing has become more common as an explicit educational aim. Despite its frequent use, it is often broadly applied, and rarely explicitly defined. Typically, wellbeing is described in education policy using conceptual pairings common in political discourse, including wealth, health and happiness. Given the attention wellbeing is receiving from politicians around the world, this is an important time to consider whether common uses of the term are relevant to and resonate with those in the school context, particularly amongst those on the cusp of entry into their adult lives. Here, I present data collected over a three-day teaching and learning event in which students were invited to share their understandings of wellbeing as they worked to accomplish tasks related to their school examinations. I analysed data through the conceptual lens of Soutter, Gilmore and O'Steen's (2010) framework for wellbeing. My central finding was that students conceptualise wellbeing as a multi-dimensional, complex construct that holds both instrumental and intrinsic value for them as individuals, but that educational experiences did not play a prominent role in their visual or verbal communication about wellbeing. Through the discussion in this paper I attempt to 'create space' to consider wellbeing's role in the senior secondary context.
\end{abstract}

\section{Introduction}

Wellbeing is a term that is often used and broadly applied, but rarely explicitly defined. In political discourse and popular media, wellbeing is typically discussed in terms of wealth, health or happiness (e.g. Cameron 2010; Canoy and Lerais 2007; Diener and Seligman 2004; Stiglitz, Sen and Fitoussi 2009). Academics from a wide range of disciplines have further dictated how the term is described and used. For 
example, to gauge the wellbeing of a society, sociologists have relied on indicators of social cohesion, epidemiologists on incidents of heart disease or cancer, and environmentalists on the rate of ozone depletion or weather anomalies (e.g. Dolan, Peasgood and White 2008; Helliwell and Putnam 2004; Prins and Rayner 2007). The particular disciplinary focus these and many other scholars have lent to their work has effectively broadened the ways wellbeing is conceptualised in the public eye. To date, educationalists have played a less pronounced role in the field of contemporary wellbeing studies. Therefore, there exists a gap in the literature addressing what it means to be well in contemporary schooling contexts, particularly from the perspectives of those intimately involved with the practices of teaching and learning.

Educationalists have typically relied on their own sector-specific measures to gauge student wellbeing, a concept more commonly discussed in education in terms of academic achievement, success or engagement. In today's accountability culture, test scores, attendance records, university entrance trends and international league tables are examples of common metrics. Learning to be skilful, capable and knowledgeable is foundational to education, and for life, and these are uncontested examples of what most taxpayers expect of their public school graduates. Less is known, however, about how these relate to the commonly referenced, but more vaguely defined, goals of personal, economic, societal and environmental wellbeing. In fact, considering that schooling is often viewed as the primary pathway by which many societal aims are to be realised, understanding how they relate to wellbeing is a compelling and timely issue.

In recent decades, use of the term wellbeing as an explicit educational aim has become increasingly common (White 2007). Indeed, in many developed nations public schools are charged with the responsibility of preparing youth to contribute to the wellbeing of society, typically in the form of an educated workforce and citizenry. New Zealand is one country in which this is explicitly stated in the national curriculum. For example, The New Zealand curriculum for English-medium teaching and learning in Years 1-13 (NZC) articulates that the Ministry of Education's 'vision is for young people who will seize the opportunities offered by new knowledge and technologies to secure a sustainable social, cultural, economic, and environmental future for our country' (Ministry of Education 2007, p. 8). While the language appears to align with current research pertaining to a well-lived life, extant wellbeing research typically has drawn from adult populations. Thus, questions remain regarding how these aims resonate with school-aged youth, particularly those on the cusp of adulthood.

\section{Why study wellbeing in school?}

School-based research is well-suited for, and can make a significant contribution to, the wellbeing literature. First, the range of expertise and scholarly interests represented in the typical school community is similar to that of many interdisciplinary wellbeing research teams. Within core and elective subjects, a diverse range of issues pertaining to wellbeing can be explored. For example, economics students studying national and global income inequalities could examine what Easterlin $(1974,2005)$ and others have debated for years: can money buy happiness 
(Layard 2005; Stevenson and Wolfers 2008; Vohs, Mead and Goode 2006)? Sociology students discussing possible indicators of societal wellbeing may engage in discussions about what constitutes valid and reliable measures. Must the instrument be quantitative, qualitative or both? Is one indicator sufficient, or is an index more appropriate? If so, what should be included? Are wellbeing indicators culturally relative or culturally specific? These are questions that have engaged the social indicators research community for decades, and the youth perspective may greatly enhance the continuing debate (Helliwell and Putnam 2004; Land et al. 2007; Sirgy et al. 2006).

Second, school-based research provides an important context in which researchers can conduct in-depth, prolonged observations and interviews. Qualitative methodologies, in particular, can capture the ebb and flow of the complex cultures of the educational environment, thereby complementing large-scale survey research (e.g. Denny et al. 2009, 2011; Ministry of Social Development 2010). Qualitative research can be limited, in that results may not directly generalise to other settings (Creswell 2005). However, a participant-centred qualitative study can provide detailed explanations difficult to represent on a Likert scale. Indeed, in their day-today interactions with their students, many teachers hold insights into their students' lives to which many researchers, or even parents, may not be privy. These, in turn, can be used to assist educators in other contexts with different populations of students, who aim to design educational experiences with wellbeing in mind.

Students, particularly senior secondary students in their last two years of schooling, have been an untapped resource in contemporary wellbeing research. Yet, with twelve or thirteen years to draw upon, this cohort is particularly 'information rich' (Patton 2005), and can offer important insights that junior students would not have the experience or perspective to provide. For example, they alone can explain if and how common indicators of student wellbeing - typically school exam performance reflect their capacity to 'contribute to the well-being of society' (Ministry of Education 2007, p. 8). Their insights may then inform policy makers and practitioners currently working to align curricular and assessment objectives.

However, the intense focus on school examinations at the senior secondary level poses particular challenges for researchers. In many schools, administrators and teachers are often reluctant to dedicate limited time and resources to research projects, particularly those that involve more than a brief survey. Thus, a degree of flexibility in methods, availability and role is required. Researchers must be familiar with the school ethos, operating cultures of the classroom and testing schedules in order to avoid compromising the teachers' curricular goals and assessment schedule.

For this study, I drew on ten years' experience as a senior secondary educator to develop a research method compatible with the participating teacher's praxis. Although wellbeing served as a content focus, I designed all of the research activities so that students could simultaneously learn and practice new skills, and subsequently earn credits towards their literacy standards for the National Certificate for Educational Achievement (NCEA). New Zealand's NCEA assessment program was only recently revised, and is currently the primary means by which students 
gain their educational qualifications for work or further study. As a result, this research achieves two important aims. First, it demonstrates that research can be successfully undertaken in time- and schedule-constrained contexts. Second, it shows that the topic of research inquiry can be an effective, as well as engaging means to develop skills, competencies and dispositions highlighted in the school curriculum as necessary tools for successful lifelong learners. Third, it fills an existing gap in the New Zealand education and the wellbeing literature by presenting students' qualitative understandings of and experiences with wellbeing in a senior secondary context.

The study reported here is the culminating event from a larger project that involved frequent $(\mathrm{N}=34)$ school visits to a mid-decile, co-educational school in Aotearoa New Zealand throughout the 2009 school year (February-December). The goal of the larger study was to understand how wellbeing is defined and experienced by senior secondary youth and their teachers, and to generate hypotheses about the relationships between wellbeing and educational experiences. I used classroom observations, document analyses, interviews and focus groups to answer the following questions: (1) How do senior secondary youth define wellbeing? (2) How do senior secondary teachers and school managers define wellbeing? (3) How does wellbeing relate to the educational experiences of students and their teacher in senior secondary contexts? I used a conceptual framework of wellbeing developed from a cross-disciplinary review of the literature to analyse the data and to explore the following question: (4) How does a conceptual framework of wellbeing developed from a cross-disciplinary review of the literature generalise to the observed senior secondary contexts? The study reported here focused specifically on the first question, 'How do senior secondary youth define wellbeing?'

I present my findings here as follows:

I. a discussion of the methodological approaches and brief description of the conceptual framework guiding the analysis

II. students' initial definitions of the terms 'healthy' and 'wellbeing'

III. a brief overview of the ways in which wellbeing is defined and used in New Zealand's national curriculum statement, The New Zealand curriculum for English-medium teaching and learning in Years 1-13

IV. findings and analysis of participants' understanding and experiences of wellbeing, organised within the lessons' main activities: visual art, smallgroup discussion, hauora model walkabout

V. discussion of the themes that emerged from the analysis

VI. consideration of findings for their potential contribution to the design and implementation of wellbeing-enhancing educational experiences.

\section{Method}

This participant observation study involved close involvement with a small group of senior secondary students engaged in educational experiences related to gaining credits towards their NCEA qualifications. As this portion of the study took place in the third of four academic terms, I had already gained a familiarity with the classroom cultures, and had developed a comfortable, working relationship with the 
students. Thus, I had the opportunity to gain valuable insights into participants' understandings of wellbeing while also working with students as they learned and practised valuable skills. Transitioning between these roles was a natural process for me, as my personal teaching philosophy involves engaging my students as 'researchers' in their own learning process.

\section{Sample}

Seventeen Year 13 students enrolled in Independent English (IE) were invited to participate in the three-day teaching and learning event. According to their teacher Jan (a pseudonym), IE was designed to cater to students who had elected, or who had been assigned, to a learning environment designed for students to work at their own pace and with individual attention from the teacher. Most students were working towards NCEA level 1 and 2 (of 3 levels). Jan anticipated that upon achieving their level 2 credits many students would choose to transfer to another class, or leave school entirely, as some felt level 2 was sufficient to enter into the workforce or further training opportunities. According to Jan, the majority of students planned to enter the workforce after they completed their necessary qualifications in literacy and numeracy, although a small number intended to pursue further training at the local polytechnic.

\section{Procedure}

The activities related to this teaching, learning and research event were designed to follow the guidelines of the NCEA program, as well as the expectations of the teachers, school and national curriculum. These were further informed by at least three primary teaching- and research-related objectives:

- to provide an opportunity for students to demonstrate their skills and competencies related to giving and receiving feedback and subsequently earn credits towards Unit Standard 9705 (Version 4 - level 3/credit 3)

- to observe students working in small- and large-group exercises, using a variety of pedagogical tools.

- to engage students in critical discussion about the topic of wellbeing in order to elicit a youth perspective.

Students' participation over the three days, and their effective demonstration of skills related to giving and receiving feedback, qualified them to receive up to three credits towards their level 3 NCEA. Specific foci for the assessment were students' capacity to self-monitor and self-evaluate; students were expected to reflect on their own capabilities and weakness, as well as to comment constructively on their peers' contributions, progress and levels of achievement. Although I designed and implemented the lessons, the teacher evaluated the students' written course evaluations, and observed students as they verbally exchanged feedback with their peers after the exercises had been completed.

Over the course of the three class periods, students engaged in a variety of activities, including visual art, walk-about discussions, surveys and small-group work. Each activity was designed to elicit students' understandings of wellbeing through these 
different media. The class periods, which ranged from 50 to 60 minutes, spread across four days due to a rotating schedule. Class meetings occurred in a room other than their usual classroom, which allowed students to sit facing one another in a large circle, while providing sufficient space for them to move freely around the room. I paid attention to effective teaching and learning strategies when designing the task. Specifically, the task afforded students time to reflect quietly, to use different media to express their thoughts (e.g. visual art, writing, debate, role playing), and to 'create space' for the subject - wellbeing - to be the central focus (Palmer 1998). As students engaged with their work, I walked around the class, listening to students, asking questions, and responding to their queries when they requested assistance. The general behaviour was respectful and jovial, and conversations focused mainly on the tasks at hand.

\section{Analysis}

I analysed and interpreted the data using the analytical tool of Soutter, Gilmore and O'Steen's (2010) conceptual framework for wellbeing. This framework, which is explained in detail elsewhere (Soutter, Gilmore and O'Steen 2010), is based on a cross-disciplinary review of the wellbeing literature. In this model, wellbeing is conceptualised in terms of seven broad domains: having, being, relating, thinking, feeling, functioning and striving, organised further within three overarching domains: appraisals, assets and actions. The thinking and feeling domains represent the ways in which people cognitively and affectively appraise their personal identities, their relationships, as well as what they have. These, conceptualised as the domains being, relating and having, respectively, provide the assets with which people engage in the actions of wellbeing, represented by the domains functioning and striving. Taken together, these domains are considered important components of the well-lived life.

\section{Findings}

During the second class meeting of the school year, Jan offered to leave the room to allow the students to speak freely about what she felt to be an important, but possibly controversial, topic. During the ensuing conversation, students were invited to comment on three possible research topics: the newly revised NCEA assessment scheme, health and wellbeing, and curriculum development. The term 'health' was initially included as a research focus as it frequently appeared in conjunction with the term 'wellbeing'. Nearly all of the 22 students present that day felt that it was important for adults to understand the students' perspectives on testing, as well as health and wellbeing. However, there was some debate about which topic should receive more focused attention. For example, one student suggested the testing scheme would be 'the easiest one to do, because we are right in the middle of it. It seams [sic] the most easiest [sic] because many of us have a clear view about it and weather [sic] or not we like it'. This discussion revealed that students' interest in the health and wellbeing topic was personally relevant and, therefore, of a more immediate concern to them. This became evident in their enthusiastic participation in the following discussions, summarised below, in which they attempted to define each construct. 


\section{How do students conceptualise health?}

Students' initial responses to queries about the definition of the term 'healthy' yielded the following:

- $\quad$ fit

- able to run long distances

- happy

- able to have food

- able to have money to eat

- exercise

- $\quad \mathrm{pH}$ of 6.9

- $\quad$ sports

- $\quad$ good family background.

These responses are notable for their apparent alignment with research-based wellbeing indicators (Cummins 2000; Deci and Ryan 1985; Diener and Seligman 2004; Huppert et al. 2008; Ryan and Deci 2000; Ryff 1989; Ryff and Singer 1998; Seligman 2002), although they appear to hone in on the physical aspects of health.

\section{How do students conceptualise wellbeing?}

In contrast, students were unable to provide a comparable list to define the term 'wellbeing', beyond 'that hauora thing'. Reference to the Maori philosophy of wellbeing suggests some students may have drawn upon their experiences in Health and Physical Education (HPE) class to define the term. According to the NZC (MOE 2007), 'the focus is on the well-being of the students themselves, of other people, and of society through learning in health-related and movement contexts' (p. 22). Hauora, along with attitudes and values, the socio-ecological perspective, and health promotion represent the 'four underlying and interdependent concepts [that] are at the heart of this learning area' (MOE 2007, p. 22). The curriculum statement for the HPE learning area, which guides teachers' curriculum design, makes specific reference to Durie's (1994) Te whare tapa wha model of hauora, which conceptualises wellbeing in terms of four, interdependent domains: physical, mental and emotional, spiritual, and social wellbeing. However, without specific reference to this model in the NZC, it remains unclear if and how teachers at the participating school utilised the model to design their educational experiences.

According to the NZC, HPE is compulsory through Year 10, thus all participating students theoretically had some exposure to the terms wellbeing and hauora. In addition, a small minority of students elected to continue their HPE studies as Year 13 students. However, even for those students currently enrolled, wellbeing appeared to be a difficult term to discuss. In her journal response to the day's discussion, one student explained, 'Wellbeing seams [sic] quite hard because I do it in health and even in that class it takes a while for things to come into my brain, and share to the class.' Another student wrote that even though the topic was as important to study as the impacts of the new assessment scheme on their lives and learning, 'total wellbeing I think would be harder to do because some stress and other things come from home! and not alot [sic] can be done about that.' The notion 
of wellbeing as situated outside of the realm of their educational experiences was also implied in another student's journal response: 'I think it is really cool that an adult is trying to understand high school students, and go to that extra mile to understand things normal teachers don't.' In sum, the diversity of topics that emerged from the first discussion regarding research topics suggested that gaining conceptual clarity on the term wellbeing was a compelling focus for the study.

\section{How is wellbeing defined in the New Zealand curriculum?}

Aotearoa New Zealand's statement of official educational policy, The New Zealand curriculum for English-medium teaching and learning for Years 1-13 (MOE 2007) refers to wellbeing in a variety of ways. As discussed above, wellbeing serves as a focal point for the HPE learning area. In addition, the curriculum's vision statement articulates that what New Zealanders 'want for our young people' are 'contributors to the well-being of New Zealand - social, cultural, economic, and environmental' (p. 8). Wellbeing is also referred to in one of four 'future focus' themes citizenship. Across learning areas, students are encouraged to explore 'what it means to be a citizen and to contribute to the development and well-being of society' ( $\mathrm{p}$. 39). In describing the role of educational experiences as a pathway towards tertiary education and employment, the NZC also refers to New Zealand's need for 'young people to be skilled and educated, able to contribute fully to its well-being, and able to meet the changing needs of the workplace and the economy' (p. 42). These references reflect a view of wellbeing common in political discourse today; wellbeing is tied to the economic growth and productivity of a nation. Accordingly, wellbeing is something to be achieved when one utilises educational qualifications to gain employment thereby 'contributing' to the wellbeing of the nation. As such, it is not necessarily inherent in the educational process itself.

Despite wellbeing's presence in the national curriculum, little is known about how New Zealand students understand or experience the phenomenon. This is particularly true for those in the final years of their secondary education who will be expected to take on their roles as 'contributors' in the near future. The three-day teaching and learning event reported in the following section provides one view into a particular population of students' views about the term wellbeing.

\section{Understandings of wellbeing from a three-day teaching and learning event}

\section{Visual art}

On the first day of the teaching and learning event, the 17 students present were provided with blank paper and coloured pencils and invited to represent their understandings of wellbeing visually. The only directions provided to the students were to use the materials as tools to express themselves. For 30 minutes students were deeply engaged with their work. Following a five minute wrap-up, students were invited to share what they had drawn, and all appeared eager to do so. Initially, students shared their work in small groups of two or three, and were invited to refer to their work at any time over the next several days to support their ideas and opinions. 
Students' artwork portrayed a wide range of images, suggesting that wellbeing was conceptualised by students in broad and diverse ways. While many of the images in their drawings represented wellbeing as it is commonly depicted in political discourse and popular media (e.g. money, material objects money affords, relationships, health, hobbies), also present were images less commonly addressed. For example, many students drew images of nature (e.g. mountains, the beach, trees, the Earth). Students' images revealed that the importance they grant to the natural environment could be a salient connection point for their learning. In fact, Gruenewald advocated 'place-based pedagogies' that educate in ways that will impact on the 'wellbeing of the social and ecological places people actually inhabit' (2003, p. 3).

In recent years, spirituality and religiosity have each gained a more prominent presence in the wellbeing literature, as integral not only to spiritual, but also to physical, relational and emotional dimensions of wellbeing (Damon 2004; Kline 2008; Lerner and Overton 2008). This research suggests that it may be the experience of feeling connected to something other than oneself, or an experience of transcendence, that relates to enhanced wellbeing (see also Cloninger 2004). However, only two students made references to experiences of spirituality or religiosity in the form of the words 'Jesus' and 'the man upstairs'.

Central to many students' drawings were images or words related to independence, such as financial freedom, having 'alone time' or 'being who you are'. Notably, all of the drawings that included individual-focused images also depicted words or images referring to relationships with others. While adolescents are often portrayed as egotistical, or consumed by a focus on their own personal identity or selfhood, these images suggested that, far from competing for attention, both relationships and personal time contributed to students' understanding of wellbeing. Vohs and Finkel (2006) provided numerous examples to argue that traditional scholarship exploring the self and relationships as separate entities may deserve reconsideration, given the inextricable ties most people experience between their personal and social identities, and the web of relationships that contribute to defining them.

The data suggests that students relate wellbeing to all seven domains of the conceptual model, although some received greater emphasis in the drawings than others. For example, all 17 drawings referred to some type of activities, interests, hobbies or involvements associated with the functioning domain. The relating domain was also well-represented, with all but one of the 17 drawings displaying images or words associated with friends, family or connections to someone or something beyond the self. Material objects or pecuniary-related images or words were included in 14 of the 17 drawings. Eight of the 17 drawings referenced pictures or words related to feelings such as happy faces, 'feeling good' or 'fun'. Least represented in words or images were the thinking and striving domains. Neither school nor learning were mentioned in any of the drawings and, with the exception of the two phrases listed in Table 1, no other mention was made of wellbeing indicators associated with the thinking domain in the literature (e.g. choices or decision making, cognitive appraisals, etc.). The lack of references to the future, or 
striving towards goals is notable, and suggests that students' present circumstances may be most pertinent for their understandings of wellbeing.

Table 1: Examples of students' visual images and phrases categorised into Soutter, Gilmore and O'Steen's (2010) conceptual framework for wellbeing

\begin{tabular}{ll}
\hline Having & $\begin{array}{l}\text { \$ signs; bills or coins, 'earning my own money'; 'things that } \\
\text { mean a lot to me (e.g. my car)' }\end{array}$ \\
Being & $\begin{array}{l}\text { 'independence'; 'alone time'; 'health'; 'safety'; 'freedom'; } \\
\text { 'being who you are or who you want' }\end{array}$ \\
Relating & $\begin{array}{l}\text { 'my old man'; 'friends and family'; nature images; 'the man } \\
\text { upstairs'; pets; 'trust' }\end{array}$ \\
Thinking & 'your mind'; 'don't take life and things for granted' \\
Feeling & $\begin{array}{l}\text { Laughter; smiles; 'fun'; 'feeling good about myself'; 'having } \\
\text { someone to talk to when I'm down' }\end{array}$ \\
Functioning & $\begin{array}{l}\text { 'hip hop'; images of sport, travel, alcohol; music; 'the way } \\
\text { someone lives' }\end{array}$ \\
Striving & 'being who you are or who you want'
\end{tabular}

\section{Small-group discussion}

Twenty minutes before the end of the period, students were invited to share their experiences of engaging in this exercise with their neighbours, and to share their drawings if they chose. Three questions posted on the board served to guide their discussion: (1) What is your definition of wellbeing? (2) How would you describe someone with wellbeing? (3) How does one have/get wellbeing? Following 15 minutes of small group discussion, volunteers from each group were asked to come up to the board and share their responses to the questions. This data is presented in its entirety below, organised by question. Domains of the conceptual framework that align with each response are highlighted in parentheses.

What is your definition of wellbeing?

- $\quad$ things that make you happy (having, feeling)

- $\quad$ good life e.g. healthy, wealthy (being, having)

- having friends and family with you no matter what you are going through (relating)

- $\quad$ being well, happy, body image, the way someone lives and feels; sexually active (being, feeling, thinking, functioning, feeling, relating) 
- career, what you are doing; the environment around you; wealthy, poor, crowd - hanging out with the wrong crowd; who you're with: supportive people, non-supportive (functioning, having, relating)

- hauora - different aspects of your life - family, social, etc. ... and how you feel about them. What's the best things for you to get on with family, friends (relating, feeling, having)

- $\quad$ makes you think; friendship; knowledge (thinking, relating, thinking)

- being pleased and happy with all aspects and dimensions of your life (thinking, feeling).

How would you describe someone with wellbeing?

- $\quad$ happy, healthy, fulfilled (feeling, being, thinking)

- inner piece [sic] (being)

- looking after yourself; happy, satisfied with their life (being, feeling, thinking)

- it depends on each individual - varies; content with their lives; happy, healthy, goal-orientated (being, thinking, feeling, being, striving)

- being pleased and happy with all aspects and dimensions of your life (thinking, feeling)

- someone who is happy with themselves and their surroundings, what is going on with their life, being contempt [sic] (feeling, being, relating, functioning, thinking)

How does one have/get wellbeing?

- finding thing that make them happy, achieving goals you set (having, feeling, striving)

- $\quad$ having things in life that make you feel good (having, feeling)

- $\quad$ having friends (relating)

- knowing who you are, where you stand (in your family, friends) (being, relating)

- by doing things they live [sic], stress-free, being comptempt [sic], accepting, sex, at one with selfe [sic], family (functioning, feeling, thinking, relating, relating, being, relating) 


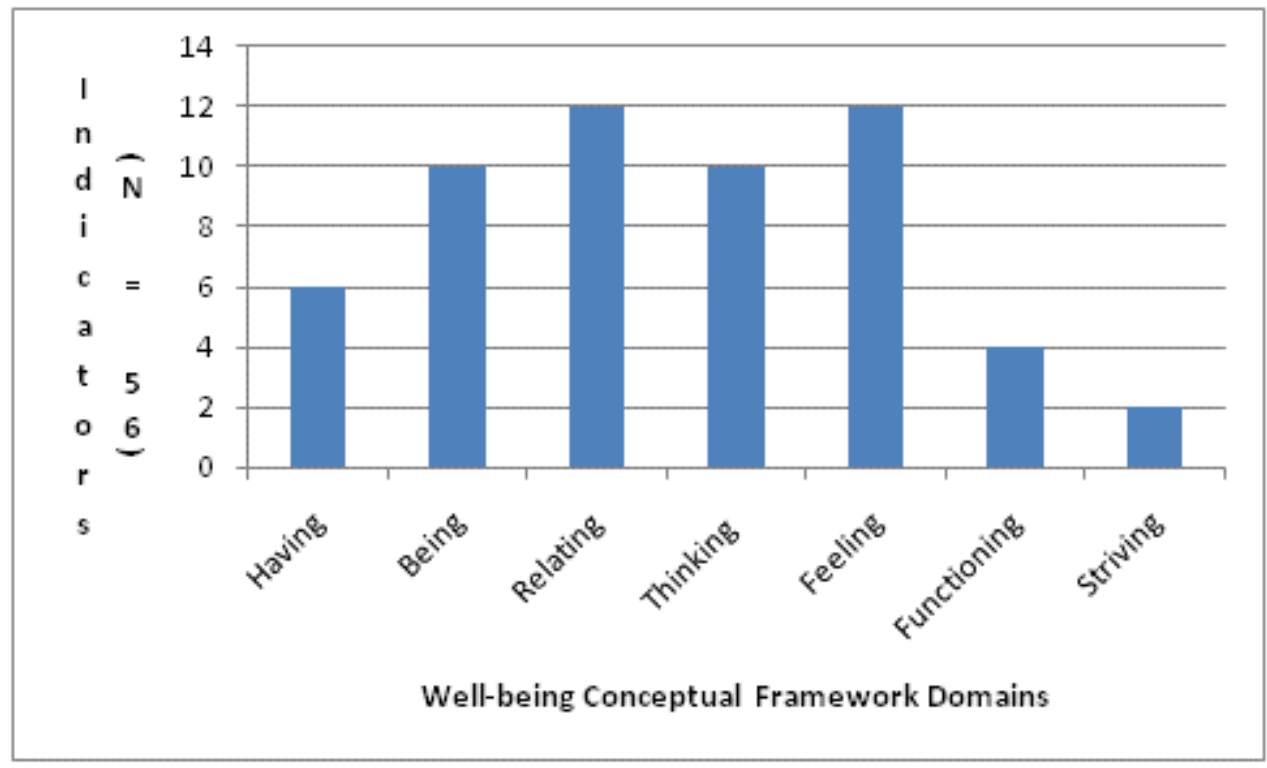

Figure 1: Distribution of students' wellbeing responses across Soutter, Gilmore and O'Steen's (2010) wellbeing conceptual framework's domains

As Figure 1 indicates, students' descriptions are distributed fairly evenly across five of the domains of Soutter, Gilmore, and O'Steen's (2010) conceptual framework. As with the visual exercise, words or phrases associated with the relating domain were among the most common, alongside the feeling domain. Notably, fewer references to the having domain and more references to the feeling domain were made when students addressed the wellbeing questions directly as opposed to the visual depictions. Also notable were the minimal number of references to the functioning domain; this may reflect an ease of translation between physical activities and the physical act of drawing, although further research is needed to explore this finding. Finally, similar to the previous exercise, references aligning with the striving domain were minimal, again suggesting a focus on students' present circumstances.

\section{Hauora model walkabout}

The second day of the teaching and learning event began with a brief review and discussion of the previous day's events, during which time students were invited to share thoughts or pose questions. Following the principles of complex instruction (Cohen 1994; Shulman, Lotan and Whitcomb 1998), students were regrouped into new teams of three. After introducing the day's objectives, I modelled the expected thinking and processing skills. Each group was then invited to stand next to one of the five sheets of butchers' paper hanging around the room. Each paper listed one aspect of wellbeing from Durie's (1994) hauora model, with one significant revision to the model. For this exercise Durie's 'mental and emotional wellbeing' category was divided into two of its component parts: cognitive/academic and emotional. Although this division is not celebrated in the Maori view of hauora (Durie, personal communication), data collected throughout the broader research project suggested a perceived conceptual separation between the two parts with respect to 
the broader notion of wellbeing. Devised in this way, this exercise provided an opportunity to consider whether the two categories would yield different or similar responses. Students' responses are presented below in the order in which they were listed as the groups moved around the room, read and could add/respond to a previous group's comments.

Table 2

\section{Domain}

\begin{tabular}{|c|c|}
\hline Social & $\begin{array}{l}\text { Lots of friends } \\
\text { Family } \\
\text { How well we relate to others } \\
\text { How we are understanding and accept others } \\
\text { Interacting with friends/family and the community } \\
\text { Friends (outside and inside); a life outside of studying, } \\
\text { family, working } \\
\text { Independent; get to have time on your own }\end{array}$ \\
\hline Spiritual & $\begin{array}{l}\text { What you believe in - values (and morals) } \\
\text { Belief in something e.g. Satan } \\
\text { Happy with yourself; be one with self } \\
\text { Based around values and beliefs }\end{array}$ \\
\hline Physical & $\begin{array}{l}\text { Healthy; fit; strong; healthy diet } \\
\text { Sport; all the physical aspects of a person like above } \\
\text { Wealthy } \\
\text { The shape, condition your body is in; health and fitness } \\
\text { Fitness, healthy, sports, exercise } \\
\text { Huge guns, lats, musty pee }\end{array}$ \\
\hline Cognitive/academic & $\begin{array}{l}\text { How well you do at school with your academic progress } \\
\text { How a person thinks and how they use there [sic] } \\
\text { cleverness in school } \\
\text { Your intelligence in school and class work } \\
\text { Personal best and nothing else matters } \\
\text { What you know about things; personal best nothing less }\end{array}$ \\
\hline Emotional & $\begin{array}{l}\text { The feelings and thoughts that a person has } \\
\text { The feelings and thoughts that a person has about } \\
\text { themselves and the people they surround themselves with } \\
\text { We agree with the top - self-esteem, how we feel towards } \\
\text { ourselves, family, friends, etc. } \\
\text { How you feel about something or someone; expressing } \\
\text { your emotions to one another } \\
\text { If your happy its all good } \\
\text { Not necessarily } \\
\text { The way you feel about yourself and others }\end{array}$ \\
\hline
\end{tabular}

How would you define wellbeing in terms of this domain? 
The nature of this exercise allowed students to engage with the comments provided by previous groups. In their discussion about the teaching and learning event, some students had articulated their appreciation for this approach; to them it felt more comfortable than a direct debate. One student shared that the exercise helped her understand that 'it's OK to voice your opinion. It's not that your [sic] being negative you are making other people think.' While the table above does not reflect the level of discussion that took place as students engaged in the activity, some responses indicate that students had read and considered previous groups' comments, and had felt inclined to address them. In the emotional wellbeing category, for example, one group responded to a previous groups' comment that 'if your [sic] happy its [sic] all good' with 'not necessarily'. This was also the category that received the most commentary by groups during the exercise, suggesting its importance to students in relation to wellbeing.

This exercise also provided an opportunity to explore how students' understandings of the hauora model compared with the conceptual model's domains of wellbeing. The indicators they provided within the categories of social, spiritual, physical, cognitive/academic and emotional wellbeing each aligned with various domains from the conceptual framework. Most closely aligned were the social wellbeing category with the relating domain, the cognitive/academic category with the thinking domain, and the emotional wellbeing category with the feeling domain. However, within each of the hauora categories, there were indicators that aligned with multiple domains of the conceptual framework. The physical wellbeing category, for example, included indicators that would be associated with the framework domains of having, being and functioning. The hauora model also directly addressed the domain of spiritual wellbeing, which does not receive explicit focus in the framework. Students' indicators that 'values', 'beliefs' and 'morals' were important to their understanding of wellbeing suggested areas for improvement of the conceptual framework in ways that better resonate with New Zealand youth.

\section{Emergent themes}

The data presented above were collected in a teaching and learning event in which students were engaged in activities designed to help them practice and demonstrate their skills related to giving and receiving feedback. With wellbeing as the content focus, students successfully achieved the assessment-related aims while offering insightful views into their understandings of a vaguely defined and complex construct. The following themes emerged from the data, suggesting that students' conceptualisations of wellbeing fell within ten general categories: (1) money; (2) having things; (3) freedom, choice and independence; (4) health and safety; (5) nature; (6) spirituality and/or religion; (7) friends, family and pets; (8) valuing/appreciating your lot in life; (9) fun, happiness; and (10) music, sport, holidays. Table 3 organises these ten themes within the seven domains of the conceptual framework. 
Table 3: Emergent themes organised according to wellbeing framework domains

\begin{tabular}{ll}
\hline Having & $\begin{array}{l}\text { Money } \\
\text { Having things }\end{array}$ \\
Being & $\begin{array}{l}\text { Freedom, independence, choice } \\
\text { Health and safety }\end{array}$ \\
Relating & $\begin{array}{l}\text { Nature } \\
\text { Spirituality, religion }\end{array}$ \\
& Friends, family, pets \\
Thinking & Valuing, appreciating your lot in life \\
Feeling & Fun, happiness \\
Functioning & Music, sport, holidays \\
Striving & \\
\hline
\end{tabular}

As Table 3 indicates, the ten themes spread across six of the seven conceptual framework's domains. The striving domain, which in the literature relates to motivation, goals, future-orientation, and the connection between one's ends and means, was not clearly represented by the majority of the indicators offered by students. This may suggest that Year 13 students, while on the cusp of change, are still very much involved in their present circumstances. How students view wellbeing in relation to their future thus remains an important topic for future investigation, particularly given the strong future orientation apparent in the national curriculum.

\section{Discussion}

The goal of this study was to understand how wellbeing is defined and understood by senior secondary youth, and to generate hypotheses about the relationships between wellbeing and educational experiences. The central finding to emerge from the participant observation study was that wellbeing was conceptualised by students as a multi-dimensional construct that holds both instrumental and intrinsic value for students, but that educational experiences did not play a prominent role in their visual or verbal communication about wellbeing.

This study builds upon the current wellbeing literature in several ways of potential import to New Zealand educationalists. First, it offers students' perspectives on a widely used, but vaguely defined construct that is often studied using data derived from adult populations. The students in this study articulated a wide range of indicators suggesting that their views of wellbeing include, but also extend beyond, 
popular depictions that equate wellbeing with wealth, health or happiness. For example, students' connection to nature, place or their broader environment is recognised by place-based educators as salient not only to educational practice, but to broader notions of personal, societal and environmental wellbeing (Manning 1999; Penetito 2004). In addition, visual and written references to issues of spiritual or religious importance, although few, are notable, particularly given the secular nature of public schooling today.

Second, this study lent support for Soutter, Gilmore and O'Steen's (2010) conceptual framework for wellbeing. All seven domains were represented to some extent in the data, suggesting that they resonate with youths' interpretations of wellbeing. However, the frequency with which the domains were mentioned, and the form they took as they were redefined by students' indicators, differed across the activities in which students were engaged. For example, the relating domain was consistently mentioned, but the striving domain was consistently not mentioned across the different learning events. In the visual art exercise, indicators related to the functioning, having and relating domains were frequently mentioned, but in the ensuing discussion about 'what is wellbeing?' the latter two were replaced by indicators aligned with the being and thinking domains. Thus, this study offers a useful point of departure for considering how the language used in scholarly research and by senior secondary youth might be translated into a common discourse about wellbeing.

Third, this study provided a possible wellbeing framework for educators to consider as they design and implement educational experiences with wellbeing in mind. The fact that students did not mention educational experiences as they discussed, portrayed or wrote about wellbeing raises questions about their perceived relationships with students' notions of wellbeing. For example, are educational experiences considered a vehicle by which students will journey on the educational pathway towards future wellbeing? Or are they considered peripheral to what students understand about wellbeing, reflecting an individualistic, present-focused perspective? If wellbeing is viewed as important to students, should it be a part of their educational experiences? How might wellbeing be incorporated into the existing national and school curriculum? Should wellbeing be assessed, and if so how? Given the use of the term wellbeing in the statement of educational policy, it makes sense to begin to explore these questions through research projects such as these, but also through discussions with those intimately involved in the practice of schooling.

Fourth, students' enthusiasm to participate in this research suggested that not only was the topic compelling, but that the methods used were sufficiently novel to be engaging, and an effective means to gauge their understanding of wellbeing. For example, in their feedback about the drawing exercise, several students explained that this had been the first time they had done something similar since primary school. With respect to the small- and large-group discussions and debate, one student wrote of her appreciation of 'the chance to give my point of view'. Another student appreciated the three-day event as a whole, writing that for 'one week we were able to say what we felt about the school. Other times it is seen as being 
negative and it's like we aren't allowed to do it.' Other students enjoyed hearing the opinions of others, and one student wrote about the discussion of how schools might change to enhance wellbeing: 'it's good to see that the students do care enough to say what needs to be changed'. On their feedback forms, some students mentioned their surprise that I joined in the exercises with the students. One student shared her appreciation of my involvement: 'Annie was really sincere about our feelings towards these topics we have discussed.' These students' comments raised questions about the opportunities available in the school context for students to discuss, think about or act on issues related to wellbeing. Indeed, future research is needed that considers the role wellbeing plays in the day-to-day educational experiences of these students.

Finally, this study demonstrated that an educational experience designed to meet assessment-related objectives can simultaneously achieve research-related aims by placing the topic of inquiry as the content focus. As Palmer's (1998) description of a subject-centred classroom portrayed, this achieves objectives that resonate with depictions of wellbeing offered by students and throughout the literature:

A subject-centered classroom is not one in which students are ignored. Such a classroom honors one of the most vital needs our students have: to be introduced to a world larger than their own experiences and egos, a world that expands their personal boundaries and enlarges their sense of community. This is why students often describe great teachers as people who 'bring to life' things that the students had never heard of, offering them an encounter with otherness that brings the students to life as well. (1998, p. 120)

By working within existing school structures, and by forging collaborative relationships between researchers and practitioners, future scholarship may address the dearth of studies examining how senior secondary youth talk about or express their understandings about wellbeing (Burrows and Wright 2004), and add to the limited number of existing theoretical models on youth wellbeing in school (for exceptions, see Konu and Rimpelä 2002). Wellbeing has proven to be a compelling topic of inquiry, for scholars and for students, thus is well-suited to play a role as the subject around which lifelong learning evolves.

\section{References}

Burrows, L and Wright, J 2004, 'The good life: New Zealand children's perspectives of health and self', Sport, Education and Society, vol. 9, no. 2, pp. 193-205.

Cameron, D 2010, PM speech on wellbeing, 25 November, http://www.number10.gov.uk/news/speeches-and-transcripts/2010/11/pmspeech-on-well-being-57569 (accessed 21 June 2011).

Canoy, M and Lerais, F 2007, 'Beyond GDP', paper presented at the Beyond GDP Conference, Rome, 19-20 November. 
Cloninger, CD 2004, Feeling good: the science of well-being, Oxford University Press, Oxford.

Cohen, E 1994, 'Restructuring the classroom: conditions for productive small groups', Review of Educational Research, vol. 64, no. 1, pp. 1-35.

Creswell, J 2005, Educational research: planning, conducting, and evaluating, Merrill, Columbus, $\mathrm{OH}$.

Cummins, RA 2000, 'Objective and subjective quality of life: an interactive model', Social Indicators Research, vol. 52, no. 1, pp. 55-72.

Damon, W 2004, 'What is positive youth development?', Annals of the American Academy of Political and Social Science, no. 591, pp. 13-24.

Deci, EL and Ryan, RM 1985, Intrinsic motivation and self-determination in human behaviour, Plenum, New York.

Denny, S, Grant, S, Utter, J, Robinson, E, Fleming, T, Milfont, T, Crengle, S, Clark, T, Ameratunga, S, Dixon, R, Merry, S and Watson, P 2011, 'The health and wellbeing of New Zealand youth who attend secondary school: what has changed from 2001 to 2007?', Journal of Paediatric and Child Health, vol. 47, no. 4, pp. 191-197.

Denny, S, Robinson, E, Milfont, T and Grant, S 2009, Youth'07: the health and wellbeing of secondary school students in New Zealand. The social climate of secondary schools in New Zealand, University of Auckland, Auckland, http://www.youth2000.ac.nz/publications/reports-1142.htm (accessed 10 February 2011).

Diener, E and Seligman, MEP 2004, 'Beyond money: toward an economy of wellbeing', Psychological Science in the Public Interest, vol. 5, no. 1, pp. 1-31.

Dolan, P, Peasgood, T and White, M 2008, 'Do we really know what makes us happy? A review of the economic literature on the factors associated with subjective well-being', Journal of Economic Psychology, vol. 29, no. 1, pp. 94-122.

Durie, M 1994, Whaiora: Maori health development, Oxford University Press, Auckland.

Easterlin, R 1974, 'Does economic growth improve the human lot? Some empirical evidence' in Nations and households in economic growth: essays in honor of Moses Abramowitz, ed. PA David and MW Reder, Academic Press, New York, pp. 89-125. 
Easterlin, RA 2005, 'Building a better theory of well-being' in Economics and happiness: framing the analysis, ed. L Bruni and PL Porta, Oxford University Press, Oxford, pp. 29-64.

Gruenewald, DA 2003, 'The best of both worlds: a critical pedagogy of place', Educational Researcher, vol. 32, no. 4, pp. 3-12.

Helliwell, JF and Putnam, RD 2004, 'The social context of well-being', Philosophical Transactions of the Royal Society of London Series B Biological Sciences, vol. 359, no. 1449, pp. 1435-1446.

Huppert, FA, Marks, N, Clark, A, Siegrist, J, Stutzer, A, Vitters $\varnothing$, J and Wahrendorf, M 2008, 'Measuring well-being across Europe: description of the ESS Wellbeing Module and preliminary findings', Social Indicators Research, vol. 91, pp. 301-315.

Kline, KK 2008, Authoritative communities: the scientific case for nurturing the whole child, Springer, New York.

Konu, A and Rimpelä, M 2002, 'Well-being in schools: a conceptual model', Health Promotion International, vol. 17, no. 1, pp. 79-87.

Land, KC, Lamb, VL, Meadows, SO and Taylor, A 2007, 'Measuring trends in child well-being: an evidence-based approach', Social Indicators Research, vol. 80, no. 1, pp. 105-132.

Layard, PRG 2005, Happiness: lessons from a new science, Penguin Press, New York.

Lerner, RM and Overton, WF 2008, 'Exemplifying the integrations of the relational developmental system: synthesizing theory, research, and application to promote positive development and social justice', Journal of Adolescent Research, vol. 23, no. 3, pp. 245-255.

Manning, R 1999, 'History never repeats itself? Colonial historical trends confront National Administration Guidelines', New Zealand Review of Education, vol. 9, pp. 63-81.

Ministry of Education 2007, The New Zealand curriculum for English-medium teaching and learning in Years 1-13, Learning Media, Wellington.

Ministry of Social Development 2010, The social report 2010: Te pürongo orange tangata, Ministry of Social Development, Wellington, www.socialreport.msd.govt.nz (accessed 3 January 2011).

Palmer, P 1998, The courage to teach: exploring the inner landscape of a teacher's life, Jossey-Bass, San Francisco. 
Patton, MQ 2005, 'Qualitative research' in Encyclopedia of Statistics in Behavioral Science, Vol. 3, ed. BS Everitt and DC Howell, John Wiley \& Sons, Chichester, pp. 1633-1636.

Penetito, W 2004, "Theorising a "place-based" education', paper presented at the NZARE, Wellington, New Zealand, 24-26 November.

Prins, G and Rayner, S 2007, 'Time to ditch Kyoto', Nature, vol. 449, pp. 973-975.

Ryan, RM and Deci, EL 2000, 'Self-determination theory and the facilitation of intrinsic motivation, social development, and well-being', American Psychologist, vol. 55, no. 1, pp. 68-78.

Ryff, CD 1989, 'Happiness is everything, or is it? Explorations on the meaning of psychological well-being', Journal of Personality and Social Psychology, vol. 57, pp. 1069-1081.

Ryff, CD and Singer, B 1998, 'The contours of positive human health', Psychological Inquiry, vol. 9, no. 1, pp. 1-28.

Seligman, MEP 2002, Authentic happiness: using the new positive psychology to realize your potential for lasting fulfillment, Free Press, New York.

Shulman, J, Lotan, RA and Whitcomb, JA (eds) 1998, Groupwork in diverse classrooms: a casebook for educators, Teachers College Press, New York.

Siglitz, J, Sen, A and Fitoussi, JP 2009, The measurement of economic performance and social progress revisited, Commission on the Measurement of Economic Performance and Social Progress, Paris.

Sirgy, MJ, Michalos, AC, Ferriss, AL, Easterlin, RA, Patrick, D and Pavot, W 2006, 'The quality-of-life (QOL) research movement: past, present, and future', Social Indicators Research, vol. 76, no. 3, pp. 343-466.

Soutter, A, Gilmore, A and O'Steen, B 2010, 'How do high school youths' educational experiences relate to well-being? Towards a trans-disciplinary conceptualization', Journal of Happiness Studies, http://www.springerlink.com/content/1389-4978/?k=Soutter (accessed 19 August 2010).

Stevenson, B and Wolfers, J 2008, Economic growth and subjective well-being: reassessing the Easterlin paradox, NBER Working Papers 14282, National Bureau of Economic Research, Washington, DC.

Vohs, KD and Finkel, EJ (eds) 2006, Self and relationships: connecting intrapersonal and interpersonal processes, Guilford Press, New York. 
Vohs, KD, Mead, NL and Goode, MR 2006, 'The psychological consequences of money', Science, vol. 314, p. 1154.

White, J 2007, 'Wellbeing and education: issues of culture and authority', Journal of Philosophy of Education, vol. 41, pp. 17-28. 